\title{
NOVOS TIPOS DE BATATA DOCE ORIUNDOS DE MUTAÇÃO SOMĀTICA
}

\author{
A. Pais de Camargo
}

Engenheiro agrônomo, Seção de Raîzes e T'ubérculos, Instituto Agronômico de Campinas

\section{1 - INTRODUÇÃO}

A batata doce (Ipomoea batatas Iam.) é normalmente propagada por via vegetativa. Ela pode, entretanto, quando encontra condições favoráveis de clima ou quando se lhe dispensam determinados tratamentos artificiais $(3,4,12)$ florescer e frutificar abundantemente, permitindo também a propagação sexuada. Neste caso, a descendência apresenta, geralmente, grande variabilidade de formas (10), e os "seedlings" obtidos proporcionam abundante material para os trabalhos de melhoramento.

Novas formas de interêsse para o melhoramento de batata dore podem ser ainda obtidas com o aproveitamento das mutações somáticas que ocorrem com freqüência nessa espécie (5). Por êsse meio, torna-se mesmo possível, conseguir resultados bastante satisfatórios, apesar de constituir um campo de trabalhos muito restrito, pois o número de novas formas obtidas nunca poderá ser tão elevado quanto o que se pode obter por meio de sementes. Como, porém, as mutações têm maiores possibilidades de ocorrer em variedades já melhoradas, por serem, naturalmente, as cultivadas em maior escala, basta que a alteração se dê num sentido favorável para que se obtenha uma nova forma já superior à primitiva.

Muitas das melhores formas ou variedades de batata doce em cultivo, foram obtidas por mutação somática. Assim, nos Estados Unidos, as variedades comerciais Marylard Goltien, Priestiey, Prolific, Nancy Gold, Bunch Porto Rico, Unit I Porto Rico, etc., consideradas entre as melhores para diferentes condięóes, foram obtidas por êsse meio $(\mathbf{1}, \mathbf{2}, \mathbf{5}, \mathbf{8}, \mathbf{1 1})$.

No Instituto Agronômico de Campinas, até o momento, constataramse seis mutações somáticas em diferentes variedades comerciais ou clones de batata doce. Dessas mutações, duas, pelo menos, já se mostram mais interessantes que as variedades que lhes deram origem e também se comparam favorìvelmente aos melhores "seedlings" obtidos e estudados nestes últimos anos. Três das outras mutações, foram obtidas recentemente, em 1952. Não se pode ainda, por isso, apresentar dados sôbre suas possibilidades.

A descrição dessas mutações, a apresentação de algumas informações sôbre o seu valor econômico e, principalmente, a focalização das possibili- 
dades das mutações somáticas em um programa de melhoramento da batata doce, constituem objeto dêste trabalho.

\section{2 - CARACTERÎSTICAS DAS MUTAÇÕES SOMĀTICAS OBSERVADAS}

A primeira mutação somática foi encontrada em setembro de 1947 , ao ser colhido um canteiro de batata doce, da variedade 98-Castelo. Numa das plantas desta variedade, que se caracteriza por apresentar raízes de polpa creme-elara e periderme roxa, foram observadas duas raízes cuja periderme se destacava pela coloração creme, apresentando apenas as gemas roxas. Essa planta foi encontrada por um operário que, infelizmente, separou as batatas da planta, de forma que não foi possível documentar a ocorrência. A nova forma, com exceção da coloração da periderme, é em tudo idêntica à variedade original 98-Castelo, que tem hábitos e característicos morfológicos muito típicos, e se distingue perfeitamente de qualquer outra variedade conhecida em Campinas.

A segunda mutação foi observada na variedade 18 -Viçosa ou "Dahomey", em julho de 1949. Entre as raízes colhidas em um canteiro dessa variedade, foram observadas algumas com aspecto e conformação típicos, mas que apresentavam uma coloração exterior mais clara e avermelhada, diferenciando-se da côr roxo-escura das raízes normais. Enquanto na var. 18-Viçosa, o córtex é também roxo, destacando-se do cilindro central de côr creme, na mutação somática o córtex se mostra creme-claro (est. 1- $A$ ). As ramas obtidas a partir das raízes mutadas, apresentaram-se com os característicos morfológicos inconfundíveis da variedade de batata doce 18-Viçosa. Notou-se apenas leve diminuição na intensidade da coloração roxa no caule, pecíolo e nervura das fôlhas.

A terceira mutação ocorreu na variedade 39-Roxa pilosa, que se caracteriza pelas raízes inteiramente roxas, tanto externa como internamente. Em agôsto de 1951, foi encontrada uma batata dessa variedade, apresentando mancha clara na casca, de 2 a $5 \mathrm{~cm}$ de largura que tomava quase todo o comprimento da raiz. Feito um corte transversal, observou-se que o setor de tecidos internos situado abaixo da mancha e abrangendo tanto o córtex como o cilindro central se mostrava inteiramente creme, contrastando com o resto dos tecidos da raiz, cuja coloração se mantinha normalmente roxa (quimera setorial). Casos semelhantes têm sido comumente observados por outros autores $(\mathbf{5}, \mathbf{9})$.

Plantada essa raiz em viveiro, verificou-se, algum tempo depois, que apresentava abundante brotação, inclusive nas gemas localizadas nas zonas de coloração normal, cujos contornos ainda se mostravam bem visíveis. Em janeiro de 1952, cinco meses depois do plantio, foi a raiz arrancada. Distinguiam-se ainda, nessa ocasião, as ramas originárias das gemas das duas zonas. Aquelas provenientes da parte mutada mostravam-se, porém, menos arroxeadas que as da parte normal. As ramas derivadas da parte normal deram plantas idênticas às da variedade original, com raízes inteiramente roxas. As oriundas da parte diferenciada produziram plantas 

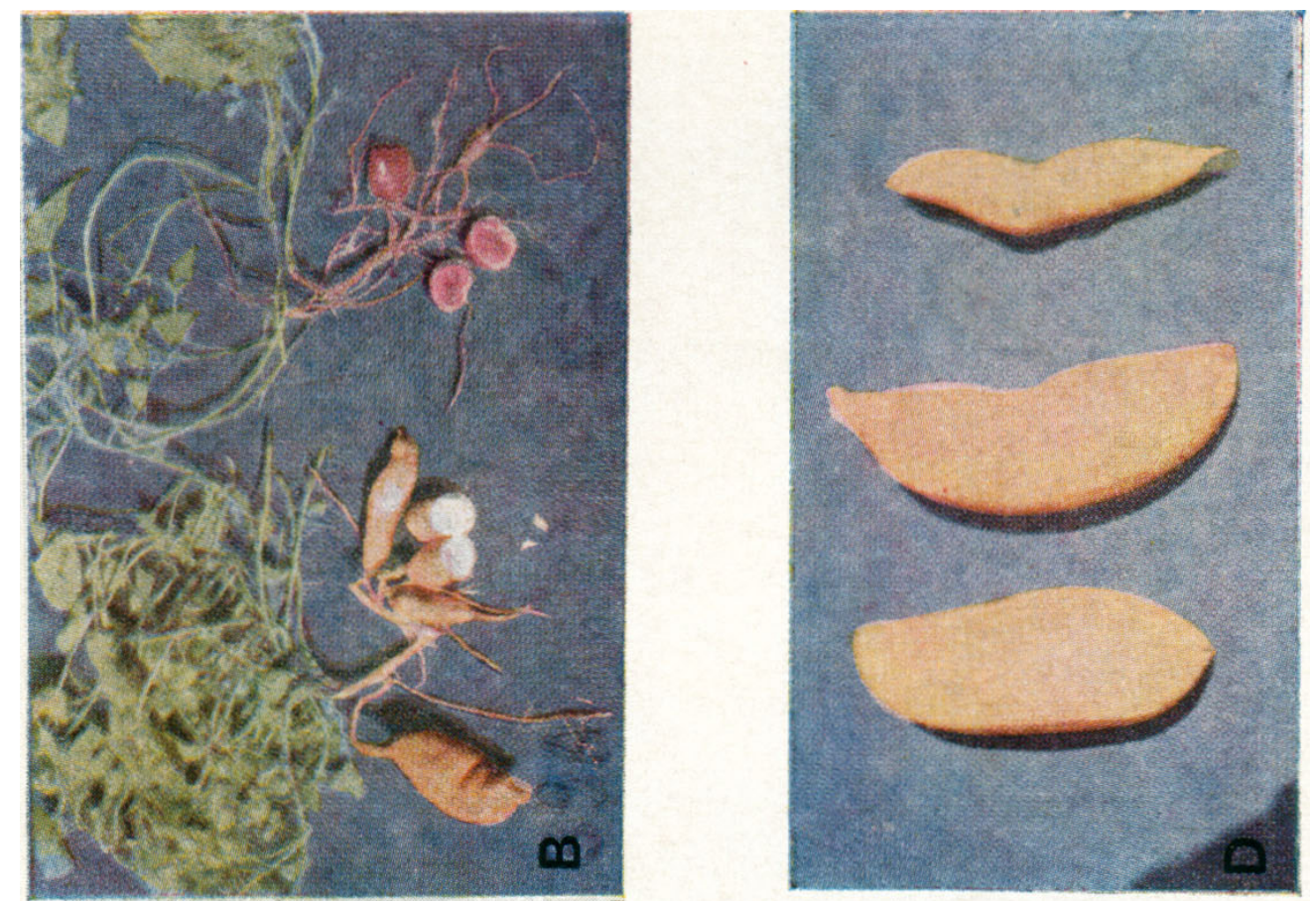

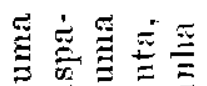
茫总芯

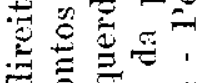

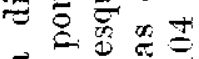

ब

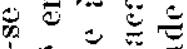

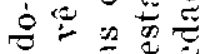

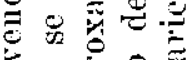
c 芯导导 氖导苋 , 忐志志望 क 5

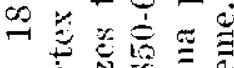

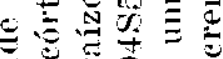
番记

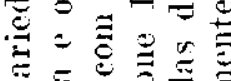
-

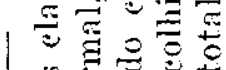
. 0

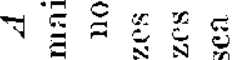
d 娄要|

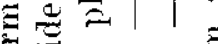

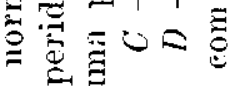

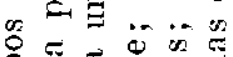

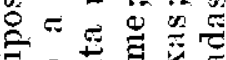

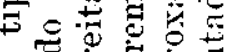

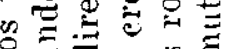
$\circ \equiv$
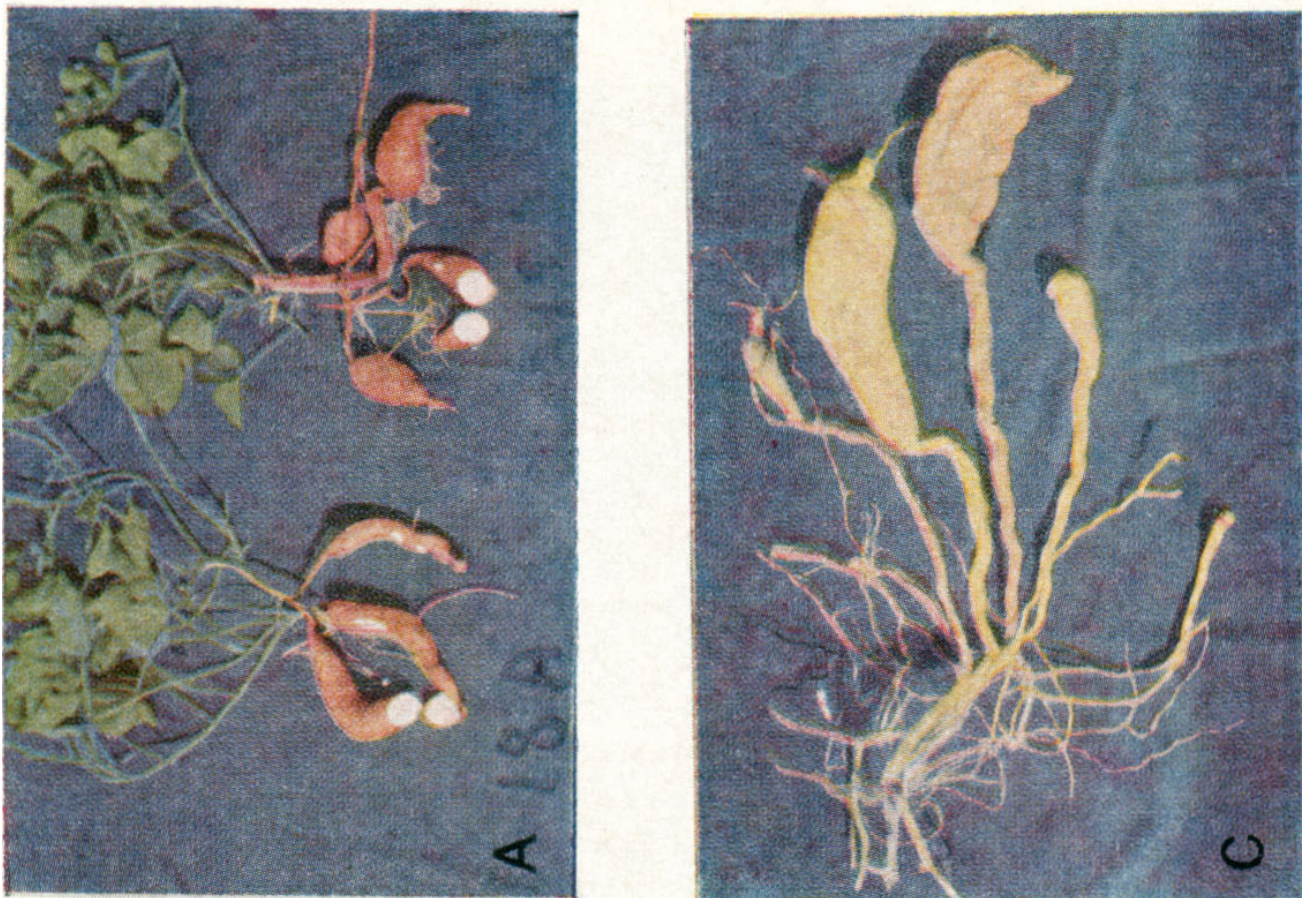

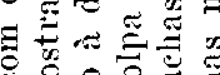
을을

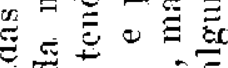
我

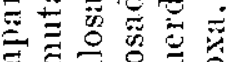

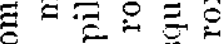
¿ 芯芯芯芯

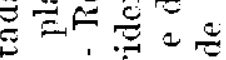
当焉焉总。

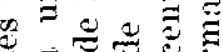

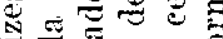

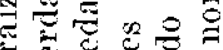

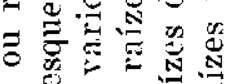
为 三 OR

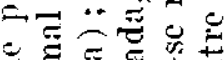
导焉焉

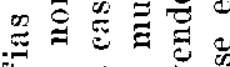
要要焉它

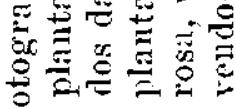


cujas raízes apresentavam a casca pardo-rosada, e o córtex, bem como o cilindro central, creme-claro (est. 1-B). Com relação às ramas, a não ser uma leve diminuição na coloração roxa do caule do novo clone, não se notou diferença alguma.

Em junho de 1952, foram encontradas mais três mutações somáticas, tôdas elas afetando a coloração da raiz. Uma ocorreu na variedade 104Peçanha rosa, há vários anos introduzida na Escola Superior de Agricultura de Viçosa, em Minas Gerais. As outras duas ocorreram em clones novos, resultantes de "seedlings" obtidos em 1950, no Instituto Agronômico.

A mutação encontrada na variedade 104-Peçanha rosa, a qual apresenta a periderme rosa-pardo e a polpa creme-claro, verificou-se em uma planta que apresentava, ao lado de várias raízes normais, algumas raízes com manchas roxas longitudinais bem como outras inteiramente roxas (est. 1-C). Aparentemente, a mutação afetou apenas a coloração da periderme da raiz.

Dentre as mutações encontradas em clones derivados de "seedlings", uma delas foi observada em um clone derivado da variedade 104-Peçanha rosa. Por ocasião da colheita de um canteiro do clone 104 S50-6, que normalmente possui raízes com a periderme roxo-forte e polpa creme, notou-se uma planta que apresentava, entre as raízes normais de casca roxa, diversas outras raízes com a casca inteiramente creme (est. 1-D) e o córtex e o cilindro central também de coloração creme.

A última mutação ocorreu em um canteiro do clone 113 S50-11, descendente da variedade 113-Ecologia. Fntre as plantas normais dêste clone, cujas raízes possuem a casca e a polpa amarelada, apareceu uma planta apresentando as raízes com a polpa fortemente roxa e a casca levemente lilás. Esta mutação resultou uma forma de carateres inteiramente originais. Fm tôda a coleção de variedades do Instituto, com cêrca de 200 tipos diferentes, em todos os milhares de "seedlings" já estudados em Campinas não havia sido observado um único que possuisse, como êste, a polpa inteiramente roxa e a periderme clara.

\section{3 - POSSIBILIDADES DAS NOVAS FORMAS}

As observações já efetuadas permitem verificar que, pelo menos as duas primeiras formas oriundas das variedades 98-Castelo e 18-Viçosa, se mostram bastante promissoras. Ambas conservam, aparentemente, as boas qualidades da forma original.

O clone resultante da mutação da variedade 98-Castelo, uma das melhores para fins forrageiros, recebeu o número IAC-98A. Com exceção da coloração da periderme da raiz, que é roxa na forma original e creme na mutada, não se observou ainda qualquer outra diferença entre estas duas formas. Ambas são muito rústicas, possuem raízes uniformes, bem conformadas, com boas qualidades culinárias e alta resistência à broca (Euscepes batatæ Waterhouse). Em ensaios de variedades realizados nestes dois últimos anos agrícolas, essas formas foram postas em competição com as melhores variedades de mesa e forrageiras da coleção. Os resultados obtidos 
mostram que tanto a forma primitiva como a nova se colocam entre as mais produtivas $(6,7)$. Desta maneira, pode-se considerar que a citada mutação passou a constituir uma das mais promissoras variedades. Em virtude da coloração clara da casca, poderá ser utilizada não só para fins forrageiros como também para o mercado, visando ao consumo de mesa.

A segunda mutação, obtida da variedade 18 -Viçosa e que recebeu o número IAC-18A, está ainda em observações. Os dados obtidos indicam, no entanto, que ela conserva os caracteres morfológicos típicos, bem como as cualidades vantajosas e a elevada capacidade de produção da variedade original que é considerada uma das melhores para fins forrageiros. A diminuição da intensidade da coloração roxa da periderme e o desaparecimento dessa côr no córtex, na forma mutada, possibilitará o seu uso também para

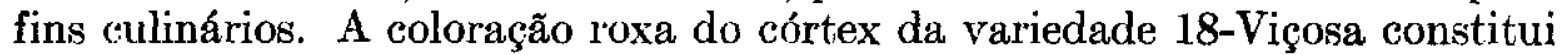
um dos seus maiores defeitos, pois quando usada para a confecção de doces essa parte da raiz precisa ser eliminada para não manchar o produto.

Com relação à terceira mutação, ocorrida na variedade 39-Roxa pilosa, e que tem número IAC-39A, e as três outras mais recentes, obtidas em 1952 , nada ainda se pode adiantar quanto às suas possibilidades econômicas.

\section{RESLMO}

As mutações somáticas que ocorrem nas variedades econômicas de batata doce podem apresentar características vantajosas, passando a constituir noros tipos comerciais, utilizados com finalidades diversas.

No decorrer dos trabalhos em realização na Secção de Raízes e Tubérculos dêste Instituto, sôbre vários aspectos agronômicos e sôbre o melhoramento da batata doce, foram observadas seis mutações somáticas, tôdas elas afetando principalmente a coloração das raízes. A descrição dessas mutações e o seu valor econômico são mencionados.

$\mathrm{Na}$ variedade 98-Castelo, a mutação afetou a côr da periderme que, de roxo, passou para creme, enquanto na variedade 18-Viçosa (Dahomey), a mudança de côr se deu na periderme e córtex que, ao mesmo tempo, de roxo mudaram para roxo-avermelhado e creme, respectivamente. Na variedade 39-Roxa pilosa, a periderme roxo-escura se tornou côr de cobre e o córtex e o cilindro central de roxo-escuro se tornaram creme. $\mathrm{Na}$ variedade 104-Peçanha rosa, a alteração ocorreu na periderme, que passou de rosapardo a vermelho-arroxeada. No "seedling" 104 S50-6, a periderme roxoescura se tornou creme, enquanto no "seedling" 113 S50-11 a periderme amarelada mudou para lilás e o córtex e cilindro central, de amarelados, passaram a ter a cốr roxa. Chamou-se atenção para a combinação de côres encontrada nesta última mutação, ainda não observada em Campinas.

Apenas as duas primeiras mutações foram estudadas quanto à produção. Verificou-se, neste particular, que se assemelham às variedades originais, as quais são das mais recomendáveis para a agricultura de São Paulo. Ambas, porém, apresentam a vantagem de possuir a casca mais clara, o que melhora sua aceitação no mercado. 


\section{SUMMARY}

During these last 5 years six somatic mutations were found in commercial varieties of sweet potatoes grown in experimental fields of the Roots and Tubers Dept. of the Insiituto Agronómico de Campinas. All these mutations affected the color of various root layers and their descriptions are presented in this paper.

In variety 98-Castelo the purple periderm became cream in the mutrated form while in the variety 18-Dahomey the purple color of periderm and cortex have been changed to purple-reddish and creum respectively. The mutation in var. 39-Roxa pilosa affected the periderm color, which changed from dark-purple to light copper and the cortex and central cylinder from dark-purple to cream color. In the variety 104-Peçanha rosa which possesses a rose-brown periderm the mutation produced a red-purplish periderm. In the seedling 104-S50-6 the dark-purple periderm became cream while in the mutated form of the 113 S50-11 seedling the yellowish periderm was changed to light-purple and the yellow cortex and central cylinder became purple. Attention has been called to the root flesh color of the seedling 113 S50-11 which is unique in the collection of sweet potatoes types at Campinas.

Only the mutations that ocurred in varieties 98-Castelo and 18-Dahomey have been tested for yield during these last two years. It has been found that both new types are similar in yield capacity to the original varieties and can be considered as very promissing types of sweet potatoes.

\section{LITERATURA CITADA}

1. Drain, Broocks E. e outros. Sweet potato eulture. Bull. Tenn agric. Exp. Sta. $189: 1-29.1944$.

2. Ifelmer, O. H. Swoet potatoes in Kansas. Bull. Kans. agric. Exp. Sta. 278: 1-5, fig. 1-11. 1938.

3. Miller, Julian C. Inducing the sweet, potato te bloom and set seed. J. Hered. 28 : $347-349$, fig. 8-9. 1937.

4. Miller, Julian C. Further studies and terhnic used in sweet potato breeding in Iouisiana. J. Hered. 30 : 485-492, fïg. 9-1.1. 1939.

5. Miller, Julian C. Further studies of mutations of the Porto Rieo sweet potato. Proc. Amer. Soe. hort. Sci. 33 : 460-465, fig. 1-2. 1936.

6. Pais de Camaryo, A. Em Relatório da Seccão de Rázes e Tubérculos do Instituto Agronômico de Campinas, 1949/50 : 39-45 (não publicado).

7. Pais de Camargo, $\Lambda$. Em Relatório da Comirsão de Plantas Tuberosas do Inetitutc Agronômico de Cumpinas, 1950/51 : (não publicado).

8. Porter, D. R. Growing and handling sweet putatoes in Califcrnia. Cire. Calif. agric. Exp. Sta. 55 : 1-3, fig. 1-12. 1931.

9. Rosa, J. 'T. Mutations in the sweet potato. J. Hered. $17:$ 167-181, fig. 3. 1926.

10. Solpico, Fabian O. A study of variability in clonal progeny of the sweet potato. Philipp. Agric. 25 : 284-294. 1937.

11. Thompson, H. C. Em Sweet potato production and handling, pag. 1-27, est. 1-9, fig. 1-3. Orange Judd Publishing Company Inc., Nova Iorque, 1929.

12. Torres, C. Barbosa. Observações preliminares sôbre o florescimento da batata doce (I pomoea batatas Poir.) Agros. Pelotas. 3 : 39-43. 1950. 